\title{
The Effect of Entomopathogenic Fungi Beauveria bassiana Seed Treatment Duration on Seed Germination and Seedling Growth of Chili
}

\author{
Trizelia, Martinius, Reflinaldon \\ Department of Plant Pests and Disease, Faculty of Agriculture, Andalas University, Padang, West Sumatra, 25163, Indonesia
}

Article Info

Received:

20 May 2020

Accepted:

07 August 2020

Published:

28 August 2020

\section{Competing Interest:}

The authors have declared that no competing interest exists.

\section{Corresponding Author:}

Trizelia, Department of Plant Pests and Disease, Faculty of Agriculture, Andalas University, Padang, West Sumatra, 25163, Indonesia

Email:trizelia@yahoo.com

(C) 2020 The Authors. This is an open access article under the CC BY license.

\begin{abstract}
Beauveria bassiana (Balsamo) Vuill. is an entomopathogenic fungus that can live endophytic on different kinds of plants. B. bassiana also play a role as growth promoters that improves seed germination and growth of the plant. B. bassiana can be introduced onto plants by soaking the seed with fungal suspension. Role as plant growth promoters of B. bassiana was affected by fungal strain and duration of the seed treatment. This study aimed to find out about the effect of the duration of B. bassiana seed treatment on seed germination and seedling growth in chili. Chili seeds were soaked in the conidial suspension of $B$. bassiana in a concentration of $1 \times 10^{8}$ conidial $/ \mathrm{ml}$ or sterile distilled water for 3, 6, 9, and 12 hours The total germination percentage of chili seeds recorded seven days post-inoculation of fungal suspension. For seedling growth, ten seeds were sown in a mixture of sterile soil and manure (1:1). This research was conducted in a completely randomized design. Radical length, shoot height, and vigor index was measured at 12 days post-inoculation. Seed germination percentages and plant growth were significantly affected by the duration of $B$. bassiana seed treatment. Overall, seed germination, the vigor index, and plant growth of chili were significantly enhanced as the duration of B. bassiana seed treatment increased. B. bassiana can also accelerate seed germination of chili and an increase of seedling growth. In this study, it concluded that soaking the seeds with a conidial suspension of B. bassiana for 912 hours is the best duration to increase seed germination and seedling growth of chili plants.
\end{abstract}

Keywords: endophyte, entomopathogenic fungi, phytohormone, vigor index 


\section{Introduction}

Beauveria bassiana (Bals.) Vuill. (Hypocreales: Cordycipitaceae) is one of the entomopathogenic fungi that has received great attention and has been used for pest control in various plant commodities (Tanada and Kaya, 1993; Zafar et al., 2016). This fungus has been used to control several insect pests such as Crocidolomia pavonana (Trizelia and Nurdin 2010). Spodoptera exigua (Razak et al., 2016), S. litura (Trizelia et al., 2016), Nezara viridula (Prayogo, 2013), Bemisia tabaci (Zafar et al., 2016), and Liriomyza sp. (Trizelia and Nelly, 2017). B.bassiana also can exist as an endophyte in many plants and causes no apparent damage to the host. Colonization of fungi in plant tissue can influence pest attacks. Endophytic B. bassiana can act as a guard that protects the plant from different pests by producing an array consists of different bioactive metabolites.

Inoculation of fava beans with fungal endophytes reduced $A$. pisum population growth by 33 times compared to the untreated plants. Feeding of Aphis gossypii on cotton leaves colonized by Beauveria bassiana has also been shown to slow aphid reproduction (Gurulingappa et al, 2010). Akello and Sikora (2012) reported that the development and performance of Acyrthosiphon pisum and Aphis fabae were adversely affected when fed on fava beans plants whose seeds were treated with endophytic fungus Beauveria bassiana at planting. B. bassiana also has been reported as an endophyte in Vicia faba and Phaseolus vulgaris, also effective at reducing the population of Liriomyza buidobrensis (Diptera: Agromyzidae) (Akutse et al., 2013). Trizelia et al. (2020) reported that B. bassiana successfully colonized various chili plant parts (leaves, stems, and roots) following seed immersion with conidial suspensions of these fungi and able to suppress development Myzus persicae.

In addition to its role in improving plant resistance against insect pests, the application of $B$. bassiana also affects the growth of plants. The growth-enhancing effect can be attributed to the ability of fungi to mobilize valuable nutrients for plant growth (Moloinyane and Nchu, 2019). Russo et al. (2019) reported that corn plants that inoculated with $B$. bassiana have seed germination percentage about $89 \%$ while non-inoculated (control) corn only $77 \%$. Afandhi et al. (2019) demonstrated that B. bassiana can be introduced onto plants by seed-soaking, leaf-spraying, and soil-wetting. The method of inoculation of $B$. bassiana can impact the growth of common bean plants. Inoculation of B. bassiana had a positive effect on plant growth parameters, which included plant height, number of leaves, and root length. Lopez and Sword (2015) reported that B. bassiana enhanced cotton growth when plants were inoculated with the fungus as seed treatment and grown under greenhouse conditions. Raya-Diaz et al. (2017) demonstrated that sorghum plants inoculated with $B$. bassiana by seed dressing were significantly taller than the ones that were inoculated by leaf spraying and soil treatment. Jaber and Enkerli (2016) reported that fungal strain of fungi and seed treatment duration also affects plant growth enhancement.

The effect of B. bassiana on plant growth of chili is important, especially in the nursery. The improvement of plant vigor to overcome biotic and/or abiotic stresses results in the production of stronger plants and increasing plant productivity and yields. Therefore, this study was designed to find out the effect of the duration of seed treatment with $B$. bassiana on the germination percentage rate and seedling growth in chili plants.

\section{Materials and Methods}

\section{A. Plant and Fungal Material}

Chili seeds used in this study were local chili varieties that were obtained from farmers in Korong Gadang village, Kuranji District, Padang City. Chili seeds were sterilized by soaking in a solution of $1 \% \mathrm{NaOCl}$ for three minutes and then the seeds were washed three times with sterilized distilled water, then were dried in a laminar airflow cabinet for 60 minutes.

Entomopathogenic fungi B. bassiana (BbWS) were isolated from Leptocorisa oratorius in Duku, Padang Pariaman District provided by the Laboratory of Biological Control, Plant Pest and Diseases Department, Agriculture Faculty, Andalas University. The fungi were propagated in Sabouraud dextrose agar plus yeast extract (SDAY) selective medium contains $0.1 \%$ antibiotic chloramphenicol. Fungi cultures were incubated for 3 weeks and conidia germination is counted before the applications. The fungal suspension was obtained by adding $5 \mathrm{ml}$ of distilled water and a $0.01 \%$ Tween 80 to a petri dish containing the cultured fungus, then the cultured fungus conidia were removed using a soft brush. The conidial suspension was filtered and then homogenized with a magnetic stirrer for 5 minutes. The concentration of conidia in fungal suspension was determined under the microscope using a Neubauer hemocytometer and adjusted to a concentration of $1 \times 10^{8}$ conidia/ml.

\section{B. Plant inoculation with $B$. bassiana}

To determine the increase of seed germination influenced by $B$. bassiana seed treatment, 25 surfacesterilized seeds were soaked in the B. bassiana conidial suspension and or in sterile distilled water containing 
Table 1. Effect of B. bassiana seed treatment duration on seed germination of chili.

\begin{tabular}{|c|c|c|c|c|}
\hline \multirow{2}{*}{ Seed Treatment Duration } & \multicolumn{4}{|c|}{ Seed Germination (\%) \pm SD } \\
\hline & 4 dpi & 5 dpi & $6 \mathrm{dpi}$ & $7 \mathrm{dpi}$ \\
\hline Control & $37.5 \pm 8.26 \mathrm{c}$ & $78.0 \pm 6.41 \mathrm{c}$ & $91.5 \pm 2.34 \mathrm{~d}$ & $91.5 \pm 3.33 \mathrm{c}$ \\
\hline 3 hours & $41.5 \pm 8.54 \mathrm{bc}$ & $78.5 \pm 4.75 c$ & $94.5 \pm 2.98 \mathrm{~cd}$ & $95.5 \pm 2.56 \mathrm{~b}$ \\
\hline 6 hours & $49.5 \pm 7.39 \mathrm{ab}$ & $82.5 \pm 4.75 \mathrm{bc}$ & $96.5 \pm 4.50 \mathrm{bc}$ & $97.0 \pm 3.55 b$ \\
\hline 9 hours & $54.0 \pm 6.41 \mathrm{a}$ & $92.0 \pm 7.09 \mathrm{a}$ & $100.0 \pm 0.00 \mathrm{a}$ & $100.0 \pm 0.00 \mathrm{a}$ \\
\hline 12 hours & $38.0 \pm 8.82 \mathrm{c}$ & $87.0 \pm 8.21 \mathrm{ab}$ & $98.0 \pm 2.14 \mathrm{ab}$ & $98.0 \pm 2.14 \mathrm{ab}$ \\
\hline
\end{tabular}

Means followed by the same letter within the same column are not significantly different at $P=0.05$ (Duncan's Multiple Range Test).

$0.1 \%$ Tween 80 (control treatment) for 3, 6, 9 and 12 hours. Then the seeds were air-dried inside the laminar airflow cabinet. The air-dried seeds were placed on $9 \mathrm{~cm}$ Petri dishes lined with moist sterile filter paper. Sterile water was added as needed to keep the filter paper moist. Eight replicate dishes were prepared for each treatment and the Petri dishes were kept in the dark condition at $20{ }^{\circ} \mathrm{C}$ for a week. A total of 200 seeds were used per treatment. The total germination percentage was recorded seven days post-inoculation.

To invests the effect of seed treatment duration on the vigor index of chili, 10 seeds were sown in pots that had contained a mixture of sterile soil and manure (1: 1). In this experiment, there were 60 seeds were used for each treatment. This experiment using a completely randomized design. The percentage of seedling emergence and vigor index was measured and observed 12 days post-inoculation. Vigor Index is calculated using the formula Abdul-Baki and Anderson (1973) which is Vigour index $=[$ Mean of root length $(\mathrm{cm})+$ Mean of shoot length $(\mathrm{cm})] \times$ percentages of seed germination.

To examine the effects of increased seed treatment duration on seedling height, inoculated or control seeds were planted in a mixture of sterile soil and manure (1:1) in pots. Two seeds of chili were sowed per pot. Plants were not fertilized through the experiment. After emergence, seedlings were thinned to one per pot and allowed to grow for 28 days. Plant height was measured in 28 days postinoculation. Plant height of chili was measured from the base of the stem to the growing point

\section{Results and Discussion}

\section{A. Effect of $B$. bassiana seed treatment duration on seed germination of chili.}

Inoculation of $B$. bassiana onto chili seeds can increase the germination percentage and speed of the germination process. Generally, the seed germination process of treated seed was significantly enhanced compared to control. Seed germination percentage of chili caused by the duration of $B$. bassiana seed treatment is shown in Table 1.

Table 1 shows the effect of seed treatment duration on the percentage of seed germination at 4, 5, 6 , and 7 days post-inoculation (dpi). Generally increasing seed treatment duration increased the percent value of seed germination. An increase in the germination of seeds after the application of B. bassiana can be caused by the fungus ability. in producing phytohormones that stimulate seed germination. Soaking the seeds of chili with B. bassiana conidia suspension for 9-12 hours produces the best seed germination compared to the others. Espinoza et al. (2019) reported that germination of chili seeds inoculated with B. bassiana BB09 and Metarbizium anisopliae MA28 strains was almost $10 \%$ greater than non inoculated control. Russo et al. (2019) also reported that corn plants that inoculated with $B$. bassiana showed an increase in the percentage of seed germination compared to control plants. Percentage of seed germination of corn in the noninoculated plant (control) only $77 \%$ while the inoculated plant with B. bassiana has the percentage of seed germination about $89 \%$. In this study, the treated seed germinated consistently faster and more uniformly than untreated seeds. Seed germination of chili from seeds that soaked in the suspension of $B$. bassiana for 9-12 hours was higher compared to seeds that soaked for 3 and 6 hours.

\section{B. Effect of $B$. bassiana seed treatment duration on the seedling growth of chili}

In seed germination, the entomopathogenic fungus $B$. bassiana also increase the seedling growth of chili. All growth parameters assessed after inoculation were significantly higher than control. Seedling growth of chili (radical length, shoot height, and vigor index) was affected by seed treatment duration of $B$. bassiana (Table 2.) 
Table 2. Effect of B. bassiana seed treatment duration on the seedling growth of chili in 12 days post-inoculation

\begin{tabular}{cccc}
\hline Seed Treatment Duration & Radical length $(\mathrm{cm}) \pm$ SD & Shoot height $(\mathrm{cm}) \pm$ SD & Vigor index \pm SD \\
\hline Control & $21.88 \pm 6.29 \mathrm{c}$ & $28.53 \pm 1.81 \mathrm{c}$ & $48.85 \pm 8.37 \mathrm{c}$ \\
3 hours & $33.07 \pm 4.63 \mathrm{~b}$ & $32.98 \pm 3.49 \mathrm{bc}$ & $62.63 \pm 5.30 \mathrm{~b}$ \\
6 hours & $30.68 \pm 6.37 \mathrm{~b}$ & $37.77 \pm 5.04 \mathrm{ab}$ & $67.20 \pm 5.20 \mathrm{~b}$ \\
9 hours & $41.42 \pm 7.35 \mathrm{a}$ & $41.07 \pm 5.45 \mathrm{a}$ & $82.48 \pm 10.76 \mathrm{a}$ \\
12 hours & $31.20 \pm 6.32 \mathrm{~b}$ & $31.58 \pm 4.93 \mathrm{c}$ & $61.85 \pm 8.03 \mathrm{~b}$ \\
\hline
\end{tabular}

Means followed by the same letter within the same column are not significantly different at $P=0.05$ (Duncan's Multiple Range Test).

It is noted that increasing seed treatment duration resulted in a marginally significant increase in the growth of inoculated plants. The growth-enhancing effect of $B$. bassiana on chili can be attributed to the ability of fungi to mobilize valuable nutrients for plant growth and also probably depends on the availability of nutrients in the growth medium. It is suspected that $B$. bassiana produces plant growth regulators such as auxins and cytokinins that promote plant growth There are several studies regarding the effect of $B$. bassiana on plant growth.

Jaber and Enkerli (2016) reported that the strain of entomopathogenic fungi and seed treatment duration had significant effects on the plant growth of Vicia faba. Inoculation with Metarbizium brunneum and $B$. bassiana significantly enhanced seedling emergence, plant height, number of leaf pairs, and fresh root weight. Increasing seed treatment duration had a significant effect on plant growth (plant height, number of leaf pairs, fresh shoot weight, fresh root weight) of Vicia faba. Increasing seed treatment duration might have caused conidia to swell and begin to germinate, and produce mucilage that could have facilitated conidial attachment to the seed. It causes the enhanced plant colonization rate and growth responses.

Kumar et al. (1999) reported that the conidia of $B$. bassiana are germinated 8 hours after inoculation on the cuticular surface of Bombyx mori larvae, but the conidial germination period varied according to the texture of the substrate and the presence or absence of nutrients. Pus (2017) reported that the root drench application of Trichoderma spp. or B. bassiana isolates to Brassica oleracea var. capitata did not significantly affect the total number of true leaves and shoot lengths, however, there was a significant effect on the root lengths. All Trichoderma spp. and B. bassiana treatments, apart from B. bassiana J18, significantly increased root length compared with the untreated control. Russo et al. (2019) reported that corn plants that inoculated with B. bassiana showed an increase in height, the number of leaves, grain weight, yield, and percentage of seed germination compared to control plants. In this study, seed treatment duration also affects the vigor index (VI) of the chili plant from treated seed with B. bassiana compared to control. The highest VI values were recorded when the

chili seed that soaked in a conidial suspension of B. bassiana for 9-12 hours. The lowest vigor index was recorded in control.

\section{Effect of B. bassiana seed treatment duration on the seedling height of chili}

Application of entomopathogenic fungi in chili by soaking the seeds also can promote the growth of seedling height. Increasing seed treatment duration also produced a significant increase in plant height (Table 3). Soaking the seeds of chili for 6 hours has been able to increase the height of chili seeds. The enhancement of plant growth of chili may be influenced by phytohormones produced by B. bassiana. The ability of the $B$. bassiana in increasing the plant height suspected by the production of growth regulators compound or the availability of nutrients for plant growth. But, the improvement of plant growth is not only resulted by $B$. bassiana isolates and plant species, but also the complex interaction of many factors such as environmental parameters, soil microorganisms, and soil-plant interaction. Raya-Díaz et al. (2017) stated that endophytic $B$. bassiana and $M$. brunneum can and can improve the iron availability, the chlorophyll content, the length of roots, and the abundance of fine roots in sorghum. Jaber and Enkerli (2016) also reported that increasing seed treatment duration of Vicia faba that were soaked in suspensions of $B$. bassiana had a significant effect on plant height. Russo et al. (2019) observed an increase of soybean plant growth after inoculated with $B$. bassiana also increase the yield of soybean plants under fields condition, with no adverse effects in the inoculated plants. 
Table 3. Effect of B. bassiana seed treatment duration on the seedling height of chili at 28 days post-inoculation

\begin{tabular}{cc}
\hline Seed Treatment Duration & Seedling height $(\mathrm{cm}) \pm \mathrm{SD}$ \\
\hline Control & $6.18 \pm 0.67 \mathrm{~b}$ \\
6 hours & $6.19 \pm 0.64 \mathrm{~b}$ \\
9 hours & $7.50 \pm 1.30 \mathrm{a}$ \\
12 hours & $8.30 \pm 0.67 \mathrm{a}$ \\
\hline
\end{tabular}

Means followed by the same letter within the same column are not significantly different at $P=0.05$ (Duncan's Multiple Range Test).

\section{Conclusions}

In this study, inoculating $B$. bassiana onto chili plants by seed-soaking treatment had a positive effect on seed germination and plant growth. Overall. increasing duration for seed treatment with $B$. bassiana was significantly enhanced the seed germination, the vigor index, and the plant growth of chili. B. bassiana also can accelerate seed germination of chili and an increase of seedling growth. The best duration of seed-soaking treatment with $B$. bassiana to increased the seed germination process and increase plant growth of chili is $9-12$ hours.

\section{Acknowledgments}

The author wishes to thank the Directorate General of Higher Education, Ministry of Research, Technology, and Higher Education research for financially supporting this through a scientific research grant offered with contract number 050/SP2H/LT/DRPM/2018.

\section{References}

[1] Abdul-Baki A. and J.D. Anderson. 1973. Vigor determination of Soybean seed by multiple criteria. Crop Science, 13: 630-633.

[2] Afandhi A., T. Widjayanti, A.A.L. Emi, H. Tarno, M. Afiyanti, and R.N.S. Handoko. 2019. Endophytic fungi Beauveria bassiana Balsamo accelerates the growth of common bean (Phaseolus vulgaris L.). Chemical, Biology, Technology, and Agriculture, 6:11.

[3] Akello J. and R. Sikora. 2012. Systemic acropetal influence of endophyte seed treatment on Acyrthosiphon pisum and Aphis fabae offspring development and reproductive fitness. Biological Control, 61: 215-221.

[4] Akutse, K.S., N.K. Maniania, K.K.M. Fiaboe, J. van den Berg, and S. Ekesi. 2013. Endophytic colonization of Vicia faba and Phaseolus vulgaris (Fabaceae) by fungal pathogens and their effects on the life history parameters of Liriomyza buidobrensis (Diptera: Agromyzidae). Fungal Ecology, 6: 293-301.

[5] Espinoza E.O., F.V. Rodríguez , P.D. Sánchezl, L.E.S.H Arteaga, J.M. Sánchez, H.M.R. Tobías, and F.V. Guerrero. 2019. Inoculation with entomopathogenic fungi reduces seed contamination, improves seed germination and growth of chilli seedlings. African Journal of Agricultural Research, 14 (32):14631471.

[6] Gurulingappa P., G.A. Sword, G. Murdoch, and P.A. McGee. 2010. Colonization of crop plants by fungal entomopathogens and their effects on two insect pests when in planta. Biological Control, 55: 34-41.

[7] Jaber L.R. and J. Enkerli. 2016. Effect of seed treatment duration on growth and colonization of Vicia faba by endophytic Beauveria bassiana and Metarbizium brunneum. Biological Control, 103:187-195.
[8] Kumar V., G.P. Singh, A.M. Babu, M.M. Ahsan, and R.K. Datta. 1999. Germination, penetration, and invasion of Beauveria bassiana on silkworm, Bombyx mori, causing white muscardine. Italian Journal of Zoology, 66 (1): 39-43.

[9] Lopez D.C. and G.A. Sword. 2015. The endophytic fungal entomopathogens Beauveria bassiana and Purpureocillium lilacinum enhance the growth of cultivated cotton (Gossypium hirsutum) and negatively affect the survival of the cotton bollworm (Helicoverpa zea). Biological Control, 89:53-60.

[10] Moloinyane S. and F. Nchu. 2019. The Effects of endophytic Beauveria bassiana inoculation on infestation level of Planococcus ficus, growth and volatile constituents of potted greenhouse grapevine (Vitis vinifera L.) Toxins, 11:72

[11] Prayogo Y. 2013. Patogenisitas cendavan entomopatogen Beauveria bassiana (Deuteromycotina: Hyphomycetes) pada berbagai stadia kepik hijau (Nezara Viridula L.). J. HPT Tropika. 13 (1): $75-86$

[12] Pus W. 2017. Plant-mediated effects of Trichoderma spp. and Beauveria bassiana isolates on insect and pathogen Resistance. [Thesis]. Lincoln University. New Zealand. 62 p.

[13] Raya-Diaz S., A.R. Sanchez-Rodriguez, J.M. Segura-Fernandez, M.C del Campillo, and E. Quesada-Moraga. 2017. Entomopathogenic fungi-based mechanisms for improved $\mathrm{Fe}$ nutrition in sorghum plants grown on calcareous substrates. PLOS ONE, 12 (10): e0185903.

[14] Razak N.A., B. Nasir, and N. Khasanah. 2016. Efektifitas Beauveria bassiana Vuill terhadap pengendalian Spodoptera exigua Hubner (Lepidoptera : Noctuidae) pada tanaman bawang merah lokal Palu (Allium Wakegi). e- J. Agrotekbis 4 (5) : 565-570

[15] Russo M.L., S.A. Pelizza, M.F. Vianna, N. Allegrucci, M.N. Cabello, A.V. Toledo, C. Mourelos, and A.C. Scorsetti.2019. Effect of endophytic entomopathogenic fungi on soybean Glycine max (L.) Merr. growth and yield. Journal of King Saud University - Science, 31: 728-736.

[16] Tanada, Y. and H.K. Kaya, 1993. Insect Pathology. Academic Press, INC. Harcourt Brace Jovanovich, Publisher. San Diego.

[17] Trizelia, Martinius, Reflinaldon, Y. Liswarni, F.S. Putra. 2020. Colonization of Beanveria bassiana (bals.) Vuill on chili (Capsicum annum) and its effect on populations of Myzus persicae. Journal of Biopesticides, 13 (2):40-46.

[18] Trizelia and N. Nelly. 2017. Peningkatan persistensi dan keefektifan formulasi agens hayati beawveria bassiana untuk pengendalian hama bawang merah. In: Prosiding Lokakarya dan Seminar Nasional FKPTPI Universitas Pattimura Ambon, October 12-13, 2017. Pp 100-109.

[19] Trizelia and F. Nurdin. 2010. Virulence of entomopathogenic fungus Beauveria bassiana isolates to Crocidolomia pavonana $\mathrm{F}$ (Lepidoptera: Crambidae). Jurnal Agrivita, 32 (3): 254-260.

[20] Trizelia, Reflin and W. Ananda. 2016. Virulensi Beberapa Isolat Cendawan Entomopatogen Endofit Beauveria Bassiana Bals. Terhadap Spodoptera litura F. (Lepidoptera:Noctuidae). In: Prosiding Semirata BKS-PTN Wilayah Barat Bidang Ilmu Pertanian, Lhokseumawe Agustus 4-6, 2016. Pp. 409-415.

[21] Zafar, J., S. Freed, B.A. Khan, M. Farooq. 2016. Effectiveness of Beauveria bassiana against cotton whitefly, Bemisia tabaci (Gennadius) (Aleyrodidae: Homoptera) on the different host plants. Pakistan Journal of Zoology, 48 (1): 91-99 